\title{
Impact of using essential drug list: analysis of drug use indicators in Gaza Strip
}

R. Fattouh ${ }^{7}$ and B. Abu Hamad ${ }^{7}$

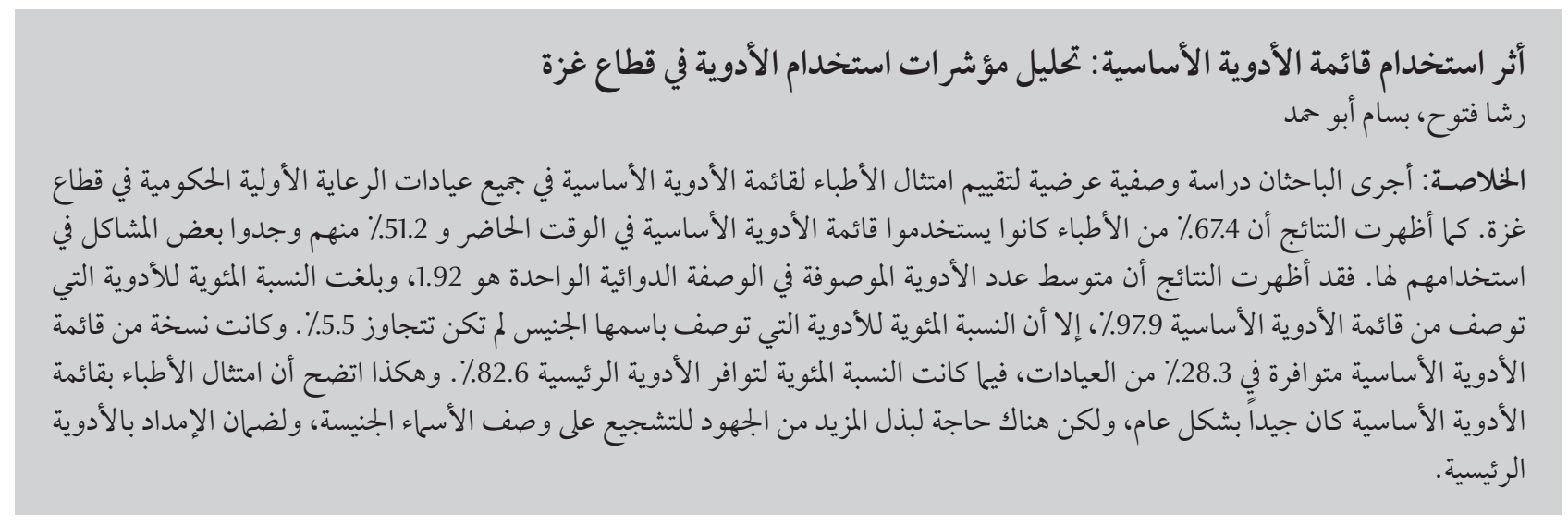

ABSTRACT A descriptive cross-sectional study evaluated the compliance of physicians with the Palestinian essential drug list (EDL) in all the government primary care clinics in the Gaza Strip. While $67.4 \%$ reported currently using the EDL $51.2 \%$ of these physicians reported problems in using it. The mean number of drugs per prescription was 1.92, the percentage of drugs prescribed from the EDL was $97.9 \%$ but the percentage of drugs prescribed by generic name was only $5.5 \%$. A copy of the EDL was available in $28.3 \%$ of clinics and the availability of key drugs was $82.6 \%$. The compliance of physicians with the EDL was generally good, but more efforts are needed to encourage prescribing by generic name and to ensure the supply of key drugs.

Impact de l'utilisation de la liste des médicaments essentiels : analyse des indicateurs d'utilisation des médicaments dans la Bande de Gaza

RÉSUMÉ Une étude transversale descriptive a évalué la manière dont les médecins respectaient la liste de médicaments essentiels palestinienne dans l'ensemble des centres de soins de santé primaires publics de la Bande de Gaza. Si 67,4 \% des médecins ont affirmé recourir à cette liste, 51,2 \% d'entre eux ont déclaré rencontrer des problèmes lors de son utilisation. Le nombre moyen de médicaments par prescription était de 1,92; le pourcentage de médicaments prescrits à partir de la liste était de 97,9\%, mais le pourcentage de médicaments prescrits par nom générique atteignait seulement 5,5\%. Un exemplaire de la liste était disponible dans 28,3\% des centres et les principaux médicaments étaient disponibles à 82,6\%. En général, les médecins se conformaient bien à la liste des médicaments essentiels, mais des efforts supplémentaires pour encourager la prescription de médicaments par leur nom générique et pour assurer l'approvisionnement en principaux médicaments essentiels doivent être réalisés. 


\section{Introduction}

Since 1994, there have been 4 major players involved in the health services of the Palestinian territories: the Ministry of Health $(\mathrm{MOH})$, the United Nations Relief and Works Agency for Palestine Refugees in the Near East (UNRWA), various nongovernmental organizations (NGOs) and the private sector. The $\mathrm{MOH}$ is responsible for providing a significant portion of the primary health care (PHC), secondary care and some tertiary care [1]. In 2005, the $\mathrm{MOH}$ spent $17.9 \%$ ofits total budget on pharmaceuticals [1]. Research findings indicate that over-prescribing, irrational prescribing and prescribing expensive brand-name drugs are common in Palestinian health facilities [2].

The development of the Palestinian essential drug list (EDL) in 2000 was an important step towards rational prescribing [3]. In line with World Health Organization (WHO) suggestions, the present study was designed to provide guidelines for updating the EDL. Uniquely, the study explored physicians' compliance with the EDL within the Palestinian context, which is characterized by diverse socioeconomic, political and managerial challenges.

The general objective of the study was to evaluate the compliance of physicians with the Palestinian EDL in government PHC facilities in order to highlight measures to improve the utilization of the EDL, thus contributing to health system efficiency and effectiveness. The specific objectives were to assess physicians' prescribing practices with reference to selected WHO indicators; to appraise physicians' attitudes and practices regarding the Palestinian EDL; to examine the relationship between prescribing practices and other variables; and to identify strengths and weaknesses in physicians' prescribing practices with reference to compliance with the EDL.

\section{Methods}

This was a cross-sectional descriptive analytical study with a self-administered questionnaire to physicians and an analysis of prescriptions collected from PHC clinics.

\section{Sample}

Because the study population is small, all 276 physicians working in government PHC clinics in Gaza Strip were recruited for the questionnaire survey. For the prescribing analysis a retrospective multi-stage random sample of 1656 prescriptions from the previous 6 months were selected. In compliance with WHO guidelines, 36 prescriptions were taken from each of the 46 clinics [4].

Because the study included all the clinics, the time-scale for the study was limited and it was difficult to access older prescriptions, therefore a time interval of 6 months was judged to be sufficient to monitor prescriptions, based on the WHO guidelines [4]. Because drug availability varies across the days of the month, 3 prescriptions were randomly drawn from each month and for each group ( $<3$ years and $\geq 3$ years): 1 from the first 10 days of the month, 1 from the middle 10 days and 1 from the last 10 days.

\section{Data collection}

Two instruments were used. The first was a self-administered questionnaire distributed to physicians to collect some relevant organizational and personal data and to assess their attitudes and practices towards the EDL.

The second was a checklist using the WHO recommended format to record selected WHO drug use indicators [4]. The researcher and 2 trained assistants filled the checklist. The mean number of drugs prescribed per encounter, the percentage of drugs prescribed by generic name and the percentage of drugs prescribed from the EDL or local formulary were calculated using standard methods [5]. The survey also checked the percentage availability of 12 key drugs in the surveyed clinics and whether a copy of the EDL or formulary was available at the health facilities. The short-list of key drugs that are essential to treat common health problems were drawn up after discussions with key stakeholders and policy-makers [6]. The researcher reviewed the filled questionnaires and checklists and entered them into the database.

Official approval to conduct the study was obtained from the research ethics committee in the Gaza Strip. Additionally, the $\mathrm{MOH}$ officially approved conducting the study and provided access to the study population.

\section{Data analysis}

Prescribing indicators were analysed by patient's age group, time of the month, governorate and by health care facility level. Because the local health system treats patients who are younger than 3 years in a different way from older patients, the prescriptions from each month in each clinic were divided into 2 groups: patients aged $<3$ years (treated free-of-charge) and patients aged $\geq 3$ years (medical insurance required) [4]. The health care levels were defined as follows: level 1 (clinic has a community health worker and a nurse all weekdays and is visited twice per week by a physician); level 2 (physician and full-time nurse work in the clinic all weekdays); level 3 (physicians and nurses work all weekdays and the clinic provides basic laboratory services, X-ray, dental care and emergency care 12 hours daily); level 4 (full-time physicians, nurses, laboratory services, ultrasound, X-ray, family planning and emergency care 24 hours daily in addition to some specialty services).

Data entry, cleaning and analysis was done using SPSS software, version 11. Descriptive analysis and then inferential analysis were done based on the nature of the study variables. Means and standard deviations (SD) were computed for 
the continuous numeric variables followed by recoding of certain variables. The selected WHO drug use indicators were computed using the statistical formulae developed by WHO. In order to explore the potential relationships between the study variables, advanced statistical analysis were conducted, including independent $t$-test, 1-way analysis of variance and the chi-squared test for categorical variables. $P$-value $<0.05$ was considered statistically significant.

\section{Results}

\section{Physicians' knowledge, attitudes and practices}

A total of 242 out of 276 physicians completed the questionnaire, a response rate of $87.7 \%$.

Only $2.8 \%$ of respondents had been involved in the preparation of the EDL, $34.4 \%$ had attended training courses on the EDL and $88.9 \%$ were interested in having further training (Table 1). Only two-thirds of physicians (67.4\%) reported currently using the EDL, and around half of this subgroup (51.2\%) said they faced many problems in using the EDL, especially concerning inadequate supplies of the listed drugs.

Table 2 shows the responses of physicians according to whether they were using the EDL or not. As expected, physicians who reported that EDL drugs were exclusively available in their clinics (94.1\%) were using EDL drugs more than the others and the differences between the 2 groups were statistically significant $(P<0.001)($ Table 2$)$.

Table 2 also shows that $83.1 \%$ of physicians who had undergone an evaluation of their prescribing practices were currently using the EDL. Similarly, $83.3 \%$ of those who received written feedback about their prescribing practices were using the EDL.

Physicians who had attended training courses on EDL were currently using it ( $83.1 \%$ ), a higher proportion than those who had not had training (58.6\%)

\begin{tabular}{|c|c|c|}
\hline \multicolumn{3}{|c|}{$\begin{array}{l}\text { Table } 1 \text { Attitudes and practices of physicians in Gaza Strip towards the essential } \\
\text { drugs list (EDL) }\end{array}$} \\
\hline Variable & No. & $\%$ \\
\hline \multicolumn{3}{|c|}{ Use EDL in prescribing } \\
\hline Use it currently & 155 & 67.4 \\
\hline Used in the past & 22 & 9.6 \\
\hline Don't use & 53 & 23.0 \\
\hline Total & 230 & 100.0 \\
\hline \multicolumn{3}{|c|}{ Experience problems in using EDL (if used) } \\
\hline Yes, many & 88 & 51.2 \\
\hline Yes, a few & 54 & 31.8 \\
\hline None & 28 & 17.0 \\
\hline Total & 170 & 100.0 \\
\hline \multicolumn{3}{|c|}{ Attended training courses on EDL } \\
\hline Yes & 77 & 34.4 \\
\hline No & 147 & 65.6 \\
\hline Total & 224 & 100.0 \\
\hline \multicolumn{3}{|c|}{ Involved in preparation of EDL } \\
\hline Yes & 6 & 2.8 \\
\hline No & 206 & 97.2 \\
\hline Total & 212 & 100.0 \\
\hline \multicolumn{3}{|c|}{ Interested in attending other training courses on EDL } \\
\hline Yes & 200 & 88.9 \\
\hline No & 25 & 11.1 \\
\hline Total & 225 & 100.0 \\
\hline
\end{tabular}

and the differences between the 2 groups were statistically significant $(P$ $<0.001)$. Moreover, significantly more physicians who found the EDL easy to use were currently using it (91.3\%) compared with those who perceived its use as difficult $(57.9 \%)(P<0.001)$ (Table 2).

Fewer physicians who agreed that they were strongly influenced by clients' requests for drugs were using the EDL (55.6\%) than those who reported never being influenced by clients' requests for drugs (72.4\%). The difference between the groups was statistically significant $(P=0.013)$.

\section{WHO drug use indicators}

The mean number of drugs prescribed per encounter was 1.92 (SD 0.99), with a median of 2 (range 1-8).

Table 3 shows the drug use indicators by patient's age group. The 2 age groups of patients $(<3$ years and $\geq 3$ years) had similar mean scores in all drug use indicators, and no statistically significant differences were found between them.

As shown in Table 4, there were statistically significant differences between the number of drugs prescribed per prescription with regard to the time of the month $(P<0.001)$, with the highest mean number (2.03) in the first 10 days of the month.

The mean percentage of drugs prescribed by generic name was $5.4 \%$ (SD 0.4\%), range 0\%-10.8\% (Table 5). However, as illustrated in Table 6 there were statistically significant differences between the rates of generic prescribing across governorates, with the highest percentage in Gaza governorate (10.8\%).

The mean percentage of drugs prescribed from the EDL or the formulary was $97.8 \%$ (SD 0.97), range 94.4\%-100\% (Table 5). 


\begin{tabular}{|c|c|c|c|c|c|c|c|c|}
\hline \multirow[t]{2}{*}{ Variable } & \multicolumn{2}{|c|}{ Currently using EDL } & \multicolumn{2}{|c|}{ Used in the past } & \multicolumn{2}{|c|}{ Not used at all } & \multirow[t]{2}{*}{$x^{2}$-value } & \multirow[t]{2}{*}{$P$-value } \\
\hline & No. & $\%$ & No. & $\%$ & No. & $\%$ & & \\
\hline \multicolumn{9}{|c|}{$\begin{array}{l}\text { Influence on physicians of clients' } \\
\text { request for drugs }\end{array}$} \\
\hline Very strong & 10 & 55.6 & 4 & 22.2 & 4 & 22.2 & 16.13 & 0.013 \\
\hline To some extent & 52 & 74.3 & 2 & 2.9 & 16 & 22.9 & & \\
\hline Weak & 45 & 58.4 & 14 & 18.2 & 18 & 23.4 & & \\
\hline Never & 42 & 72.4 & 2 & 3.4 & 14 & 24.1 & & \\
\hline \multicolumn{9}{|c|}{$\begin{array}{l}\text { Physicians have evaluation for } \\
\text { their prescribing practices }\end{array}$} \\
\hline Yes & 49 & 83.1 & 4 & 6.8 & 6 & 10.2 & 13.22 & 0.01 \\
\hline No & 69 & 58.0 & 15 & 12.6 & 35 & 29.4 & & \\
\hline Don't know & 33 & 73.3 & 2 & 4.4 & 10 & 22.2 & & \\
\hline \multicolumn{9}{|c|}{$\begin{array}{l}\text { Physicians receive feedback about } \\
\text { their prescribing practices }\end{array}$} \\
\hline Yes, written & 15 & 83.3 & 2 & 11.1 & 1 & 5.6 & 5.89 & 0.208 \\
\hline Yes, verbal & 55 & 71.4 & 4 & 5.2 & 18 & 23.4 & & \\
\hline None & 79 & 63.2 & 14 & 11.2 & 32 & 25.6 & & \\
\hline \multicolumn{9}{|l|}{ Ease of use of EDL } \\
\hline Yes, easy & 136 & 91.3 & 13 & 8.7 & $\mathrm{n} / \mathrm{a}$ & - & 17.17 & 0.001 \\
\hline No, not easy & 11 & 57.9 & 8 & 42.1 & $\mathrm{n} / \mathrm{a}$ & - & & \\
\hline \multicolumn{9}{|c|}{$\begin{array}{l}\text { Availability of EDL drugs in } \\
\text { the pharmacy }\end{array}$} \\
\hline Exclusively present & 16 & 94.1 & 1 & 5.9 & 0 & 0.0 & 27.33 & 0.001 \\
\hline Partially present & 118 & 73.3 & 15 & 9.3 & 28 & 17.4 & & \\
\hline No & 14 & 48.3 & 4 & 13.8 & 11 & 37.9 & & \\
\hline Don't know & 3 & 23.1 & 2 & 15.4 & 8 & 61.5 & & \\
\hline \multicolumn{9}{|c|}{ Attended training course on EDL } \\
\hline Yes & 64 & 83.1 & 8 & 10.4 & 5 & 6.5 & 19.03 & 0.001 \\
\hline No & 85 & 58.6 & 13 & 9.0 & 47 & 32.4 & & \\
\hline
\end{tabular}

$n / a=$ not applicable.

Less than $30 \%$ of surveyed facilities were able to show the research team a copy of the EDL (Table 5). Interestingly, more PHC clinics at level 3 had copies than other level clinics and this difference was statistically significant $(P$ $=0.001)$. Differences in the availability of the EDL across governorates were also statistically significant $(P=0.001)$ (Table 6).
The mean proportion of the 12 key drugs available at clinics was $82.6 \%$ (SD 15.2\%), range $41.6 \%-100 \%$ (Table 5). The researcher validated the availability of drugs listed in the EDL

\begin{tabular}{|c|c|c|c|c|c|c|}
\hline \multirow[t]{3}{*}{ Drug use indicator } & \multicolumn{4}{|c|}{ Age of patient } & \multirow[t]{3}{*}{$t$-value } & \multirow[t]{3}{*}{$P$-value } \\
\hline & \multicolumn{2}{|c|}{$\begin{array}{c}\geq 3 \text { years }(\text { insurance required) } \\
(n=849)\end{array}$} & \multicolumn{2}{|c|}{$\begin{array}{c}<3 \text { years (qualify for free } \\
\text { treatment) }(n=807)\end{array}$} & & \\
\hline & Mean & SD & Mean & SD & & \\
\hline No. of drugs per prescription & 1.93 & 1.09 & 1.91 & 0.87 & 0.458 & 0.647 \\
\hline $\begin{array}{l}\% \text { of drugs prescribed by } \\
\text { generic name }\end{array}$ & 5.2 & 0.3 & 5.8 & 0.4 & -1.020 & 0.308 \\
\hline$\%$ of drugs prescribed from EDL & 97.4 & 1.07 & 98.4 & 0.9 & 0.004 & 0.997 \\
\hline
\end{tabular}

$n=$ number of prescriptions analysed; $E D L=$ essential drugs list; $S D=$ standard deviation. 


\begin{tabular}{|c|c|c|c|c|c|}
\hline \multirow[t]{3}{*}{ Drug use indicator } & \multicolumn{3}{|c|}{ Time of month } & \multirow[t]{3}{*}{$F$-value ${ }^{\mathrm{a}}$} & \multirow[t]{3}{*}{$P$-value } \\
\hline & $\begin{array}{l}\text { First } 10 \text { days } \\
\qquad(n=552)\end{array}$ & $\begin{array}{c}\text { Days } 11 \text { to } 20 \\
\quad(n=550)\end{array}$ & $\begin{array}{l}\text { Last } 10 \text { days } \\
\quad(n=554)\end{array}$ & & \\
\hline & Mean & Mean & Mean & & \\
\hline No. of drugs per prescription & 2.03 & 1.92 & 1.81 & 7.25 & 0.001 \\
\hline$\%$ of drugs prescribed by generic name & 6.4 & 4.7 & 5.5 & 1.93 & 0.145 \\
\hline$\%$ of drugs prescribed from EDL & 97.0 & 97.3 & 98.3 & 5.38 & 0.005 \\
\hline$\%$ of key drugs available in clinics & 84.4 & 79.4 & 83.3 & 0.49 & 0.617 \\
\hline
\end{tabular}

a-way ANOVA.

$n=$ number of prescriptions analysed; $E D L=$ essential drugs list

by checking clinic pharmacies and confirmed subjects' responses, revealing availability of all 12 drugs in only $7.7 \%$ of the clinics surveyed and partial availability of the list in $73.4 \%$. Physicians reported different reasons for drug shortages, including inadequate supplies of drugs at the $\mathrm{MOH}$ central store (66.2\%), inaccurate estimation of the quantities of drugs required (35.1\%), management problems and bureaucracy $(22.5 \%)$ and a lack of financial resources $(21.2 \%)$.

\section{Discussion}

Physicians who reported that EDL drugs were exclusively available in their clinics were using EDL drugs significantly more than the others. This is a clear indication that the availability of EDL drugs in clinics encourages physicians to comply with the EDL and this stimulates the $\mathrm{MOH}$ to exert more efforts to ensure continuous availability of drugs. It was noticed that in some facilities, although the EDL was available, physicians used Medic (the Israeli drugs guide) in their prescribing, despite of the fact that Medic contains many brand-name drugs that are neither listed in the Palestinian EDL nor present in the clinic pharmacies.

More of the physicians who had undergone an evaluation of their prescribing practices $(83.1 \%)$ or who had received written feedback about their prescribing practices $(83.3 \%$ ) were currently using the EDL than the overall percentage $(67.4 \%)$. This points to the importance of monitoring and supervision as the distribution of the EDL is not adequate by itself. Physicians who found the EDL easy to use were significantly more likely to use it than those who perceived its use as difficult. Therefore health managers and other stakeholders should organize periodic assessments of the EDL and regularly update it to produce more user-friendly versions [7].

The mean number of drugs prescribed per encounter (1.92) is consistent with the international standard recommended by the WHO (below 2) [8]. It was also close to the average in Egypt, the United Arab Emirates and Morocco (2 drugs per encounter) [9-11].

There were statistically significant differences between the numbers of drugs per prescription at different times of the month. Drug orders are distributed to PHC clinics within the first 10 days of the month. As a result, patients became aware of this and tend to go to the clinics more within these days to ensure that they will receive the needed drugs. Moreover, physicians also become familiar with that situation and prescribe drugs more within the first 10 days of the month. Needless to say, there are many factors potentially contributing to the above results. In the Gaza Strip, clients have access to other health providers who freely provide drugs. Additionally, there is the phenomenon of prescribing drugs on informal prescriptions to be dispensed from private pharmacies.

\begin{tabular}{|c|c|c|c|c|c|c|}
\hline \multirow[t]{3}{*}{ Drug use indicator } & \multirow[t]{3}{*}{ Overall } & \multicolumn{3}{|c|}{ PHC level } & \multirow[t]{3}{*}{$F$-value } & \multirow[t]{3}{*}{$P$-value } \\
\hline & & Level $2(n=540)$ & Level $3(n=828)$ & Level $4(n=288)$ & & \\
\hline & & Mean & Mean & Mean & & \\
\hline No. of drugs per prescription & 1.92 & 1.99 & 1.90 & 1.84 & 2.419 & 0.089 \\
\hline$\%$ of drugs prescribed by generic name & 5.4 & 2.0 & 7.9 & 4.9 & 17.47 & 0.001 \\
\hline$\%$ of drugs prescribed from EDL & 97.8 & 97.9 & 97.3 & 98.9 & 2.596 & 0.750 \\
\hline$\%$ of key drugs available in clinics & 82.6 & 89.4 & 79.3 & 79.1 & 2.391 & 0.104 \\
\hline$\%$ of clinics with copy of EDL & 28.3 & 16.3 & 34.2 & 33.6 & 4.615 & 0.015 \\
\hline
\end{tabular}

$n=$ number of prescriptions analysed; $E D L=$ essential drugs list. 


\begin{tabular}{|c|c|c|c|c|c|c|c|}
\hline \multirow[t]{3}{*}{ Drug use indicator } & \multicolumn{5}{|c|}{ Governorate } & \multirow[t]{3}{*}{$F$-value } & \multirow[t]{3}{*}{$P$-value } \\
\hline & $\begin{array}{l}\text { North } \\
(n=252)\end{array}$ & $\begin{array}{c}\text { Gaza } \\
(n=504)\end{array}$ & $\begin{array}{l}\text { Mid-Zone } \\
(n=468)\end{array}$ & $\begin{array}{l}\text { Khanyounis } \\
(n=324)\end{array}$ & $\begin{array}{l}\text { Rafah } \\
(n=108)\end{array}$ & & \\
\hline & Mean & Mean & Mean & Mean & Mean & & \\
\hline No. of drugs per prescription & 2.07 & 1.99 & 1.86 & 1.87 & 1.62 & 5.291 & 0.001 \\
\hline $\begin{array}{l}\% \text { of drugs prescribed by } \\
\text { generic name }\end{array}$ & 5.8 & 10.8 & 3.2 & 1.1 & 0.0 & 24.01 & 0.001 \\
\hline$\%$ of drugs prescribed from $\mathrm{EDL}$ & 94.2 & 96.4 & 100.0 & 100.0 & 100.0 & 2.531 & 0.039 \\
\hline $\begin{array}{l}\% \text { of key drugs available in } \\
\text { clinics }\end{array}$ & 82.1 & 73.2 & 80.1 & 96.2 & 97.2 & 5.53 & 0.001 \\
\hline$\%$ of clinics with copy of EDL & 42.9 & 42.9 & 15.4 & 0.0 & 66.7 & 2.49 & 0.058 \\
\hline
\end{tabular}

$n=$ number of prescriptions analysed; $E D L=$ essential drugs list.

The percentage of drugs prescribed by generic name is an important element of the essential drugs concept. The rate of generic prescribing of $5.5 \%$ in our study is very low compared to the standard WHO value (100\%) [8]. Decision-makers should put more effort into increasing the knowledge of physicians about the positive impact of generic prescribing. The $\mathrm{MOH}$ also needs to promote generic drugs in all aspects of the commodity management cycle (procurement, selection and ordering). Another factor contributing to the tendency of physicians to prescribe brand-name drugs is the false impression of the public, and of physicians, that generic drugs are of poorer quality and efficacy [12].

There were significant differences between the rates of generic prescribing across governorates, with the highest rate in Gaza governorate. This could be attributed to the proximity effect, as the pharmacy management centre is based in Gaza governorate where all the implementation and training for the EDL takes place before it is rolled out to other governorates. Also, there are some PHC facilities in Gaza governorate which independently held training courses for their physicians [13].

The overall percentage of drugs prescribed from the EDL (97.9\%) is one of the highest in the world as it is near the standard value of $100 \%$ [8]. This result shows a positive result for implementation of EDL and physician compliance with it. This was achieved was mainly as a result of managerial interventions, by which all drugs provided to facilities are from the EDL. Drugs prescribed from outside the EDL were donated ones. It is therefore essential to apply WHO guidelines for drug donation, emphasizing that all drug donations should comply with the local EDL. It is worth noting that donated drugs represent an important drug resource in Palestine [14]. Ironically, the researcher noted that physicians prescribed drugs not from the EDL on informal prescriptions. This may indicate that physicians' compliance is mainly based on drug availability, regardless of whether these drugs are from the EDL or not. The fact that the $\mathrm{MOH}$ only provides drugs on the EDL list forces physicians to prescribe these available drugs without being fully aware of the value of the EDL. This calls for additional training programmes with follow-up and monitoring.

Less than $30 \%$ of surveyed facilities had a copy of the EDL, a rate much lower than the standard (100\%) [8]. This highlights the need for an appropriate dissemination plan for the EDL, followed by monitoring and supervision. Although the presence of the EDL is essential for compliance, it is not enough by itself to ensure it [15]. Dissemination of the EDL should be accompanied by training on it content and use.
The availability of key drugs was $82.6 \%$, which is low compared with the standard value advised by WHO (100\%) [8]. The lack of availability of key drugs reflects problems in the $\mathrm{MOH}$ which are frequently manifested by drug shortages in clinics [1]. Possible factors leading to drug shortages are insufficient financial resources for drug procurement, the overuse of drugs by physicians, pharmacists and patients and Israeli border closures, which delay the arrival of drugs. Additionally, most of the $\mathrm{MOH}$ drugs are funded by the World Bank through lengthy procedures which cause delay, particularly in the unstable and unpredictable political situation in the area [1]. Rational drug use here plays an important role in overcoming drug shortages; therefore, training and awareness, appropriate regulations and supervision physicians and dispensers are essential, particularly in relation to the rational use of drugs and its impact.

\section{Conclusions and Recommendations}

The compliance level of PHC physicians was generally good and could be explained mainly by managerial/regulatory factors affecting the provision of drugs that are listed on the EDL. The results of WHO drug use indicators were positive in certain aspects such as 
the low rate of polypharmacy (1.92), but negative in others such as the low rate of prescribing by generic name (5.5\%). Efforts are needed to improve the use of generic names on prescriptions, the availability of key drugs and the availability of the EDL document at clinics. Developing an effective dissemination plan for the EDL with appropriate follow up and supervision is essential, and policy-makers need to improve the drug management cycle at PHC facilities, with special attention to ensuring the availability of essential drugs $[16,17]$. Further research is needed to evaluate prescribing practices in other settings and sectors. Follow-up assessments are also recommended in the future.

\section{References}

1. Health status in Palestine. Annual report. Ramalla, Palestine, Ministry of Health, Palestinian National Authority, 2005.

2. Obeidallah W et al. Drug situation analysis for the West Bank and Gaza Strip. Geneva, World Health Organization, 2000 (EDM/ DAP/2000.1).

3. Palestinian drug formulary, 1st ed. Ramalla, Palestine, General Directorate of Pharmacy, Ministry of Health, Palestinian National Authority, 2002.

4. How to investigate drug use in health facilities. Geneva, World Health Organization, 1993 (WHO/DAP).

5. Quality assurance of pharmaceuticals. A compendium of guidelines and related materials. Volume 1. Geneva, World Health Organization, 1997.

6. How to use applied qualitative methods to design drug use interventions. Geneva, World Health Organization, 2000.

7. How to develop and implement a national drug policy. Geneva, World Health Organization, 2001.

8. Dumoulin J. Guide to drug financing mechanisms. Geneva, World Health Organization, 1998.

9. Zaki A et al. The use of medication in infants in Alexandria, Egypt. Eastern Mediterranean Health Journal, 1999, 5(2):320327.
10. Hasan M, Das M, Mourad F. Drug utilization and antibiotic use in primary health care centres in Sharjah. Eastern Mediterranean Health Journal, 1997, 3:444-451.

11. Simon $\mathrm{N}$ et al. Drug prescription and utilization in Morocco. Therapies Journal, 1998, 53(2):113-120.

12. Medical and pharmaceutical situation inside the West Bank in primary health care. Ramalla, Palestine, Pharmaciens Sans Frontieres, 2003.

13. Essential drugs list and Palestinian national formulary training course report. Quality improvement program. Ramalla, Palestine, Palestinian National Authority, Ministry of Health, 2001.

14. Kousa M et al. West Bank and Gaza Update: World Bank report on impact of intifada. A quarterly publication of the West Bank and Gaza Office. Ramalla, Palestine, World Bank, 2003.

15. Grimshaw J, Russell I. Effect of clinical guidelines on medical practice: a systematic review of rigorous evaluations. Lancet, 1993, 342:1317-1322.

16. Management Science for Health and World Health Organization. Managing drug supply, 2nd ed. West Hartford, Connecticut, Kumarian Press, 1997.

17. Practical quidelines on pharmaceutical procurement for countries with small procurement agencies. Manila, Philippines, World Health Organization Regional Office for the Western Pacific, 2002.

\section{Correction}

Evaluation of effect of silymarin on granulosa cell apoptosis and follicular development in patients undergoing in vitro fertilization. N. Moosavifar, ${ }^{1}$ A.H. Mohammadpour, ${ }^{2,3}$ M. Jallali, ${ }^{1}$ G. Karimi ${ }^{2,4}$ and H. Saberi ${ }^{2}$ Eastern Mediterranean health journal, 2010, 16(6):642-650.

The affiliation for the fourth authori should be changed from G. Karimi ${ }^{\mathbf{2 , 4}}$ to G. Karimi ${ }^{\mathbf{3}, \mathbf{4}}$.

${ }^{7}$ Women's Health Research Centre; ${ }^{2}$ Pharmaceutical Research Centre ; ${ }^{3}$ School of Pharmacy; ${ }^{4}$ Medical Toxicology Resarch Centre, Mashhad University of Medical Sciences, Mashhad, Islamic Republic of Iran. 